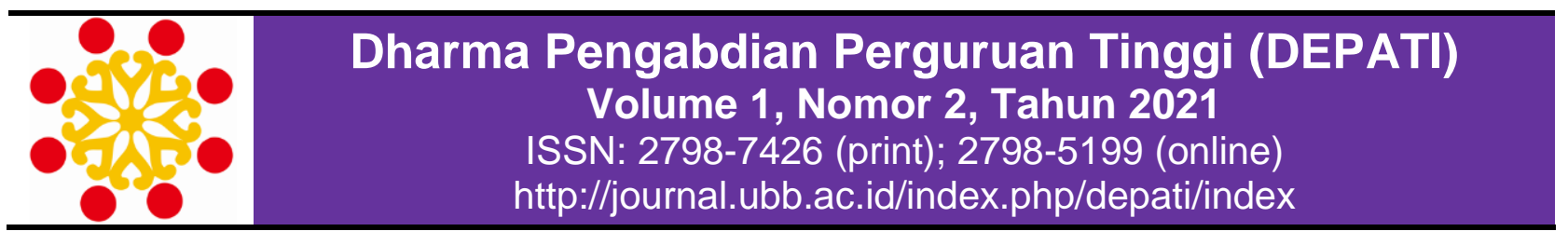

\title{
SOSIALISASI PEMANFAATAN MULTIMODEL DALAM PEMBELAJARAN PADA GURU SD NEGERI NO. 122372 PEMATANGSIANTAR
}

\author{
Juni Agus Simaremare ${ }^{1, \star)}$ dan Herna Febrianty Sianipar ${ }^{2}$ \\ 1) Prodi PGSD, Fakultas Keguruan IImu Pendidikan, Universitas HKBP Nommensen Pematangsiantar \\ Jalan Sangnaualuh No.04 Pematangsiantar, Sumatera Utara, Indonesia \\ 2) Prodi MPSDP, Fakultas FTPSDP, Universitas HKBP Nommensen Pematangsiantar \\ Jalan Sangnaualuh No.04 Pematangsiantar, Sumatera Utara, Indonesia \\ *E-mail korespondensi: simaremarejuniagus@gmail.com
}

\begin{abstract}
Info Artikel: Abstract
Dikirim:

12 Oktober 2021

Revisi:

28 November

2021

Diterima:

29 November

2021

Kata Kunci:

Sosialisasi,

multimodel,

pembelajaran

This service activity is motivated by the number of students who cannot understand the subject matter independently, students who feel bored and bored during the learning activities, and inadequate support facilities. This multimode socialization activity is for the teachers of SD Negeri No. 122372 Pematangsiantar, totaling ten people. This socialization activity was carried out on Monday-Tuesday, 23-24 October 2018, starting at 09.00 WIB. This socialization activity aims to: (1) provide knowledge to teachers of SD Negeri No. 122372 Pematangsiantar nature and implementation stages of multimodel in learning; (2) increase the creativity of SD Negeri No. 122372 Pematangsiantar in the learning process in the classroom. Implementing Community Service Activities is carried out in the form of socialization and direct practice in the classroom. This multimodel socialization activity has been carried out well according to the schedule of activities, starting from the initial, core, and final activities. The result of this service activity is that the teachers have understood the nature and stages of implementing multiple models in learning. In addition, the increased creativity of teachers in applying multimodel in learning is from the first phase to the fifth phase. It can be proven from 10 respondents that $24.04 \%$ voted strongly agree that the use of multi models in learning is essential and valuable, while $75.96 \%$ said they agreed that multi models in learning are significant and valuable.
\end{abstract}

\begin{abstract}
Abstrak
Kegiatan pengabdian ini dilatar belakangi oleh banyaknya siswa tidak mampu memahami materi pelajaran secara mandiri, siswa merasa jenuh dan bosan selama kegiatan pembelajaran berlangsung, dan dukungan fasilitas yang kurang memadai. Kegiatan sosialisasi multimode ini adalah para guru SD Negeri No. 122372 Pematangsiantar yang berjumlah 10 orang. Kegiatan sosialisasi ini dilaksanakan pada hari Senin-Selasa, 23-24 Oktober 2018 yang dimulai pada pukul 09.00 WIB. Kegiatan sosialisai ini bertujuan: (1) memberikan pengetahuan kepada guru SD Negeri No. 122372 Pematangsiantar hakikat dan tahap pelaksanaan multimodel dalam pembelajaran; (2) meningkatkan kreativitas guru SD Negeri No. 122372 Pematangsiantar dalam proses pembelajaran di kelas. Metode pelaksaan Kegiatan Pengabdian kepada Masyarakat ini dilaksanakan dalam bentuk sosialisasi dan praktek langsung di kelas. Kegiatan sosialisasi multimodel ini telah terlaksana dengan baik sesuai dengan jadwal kegiatan yaitu mulai dari kegiatan awal, inti dan kegiatan akhir. Hasil dari kegiatan Pengabdian ini adalah para guru telah memahami hakikat dan tahap pelaksanaan multi model dalam pembelajaran. Selain itu meningkatnya kreatifitas guru dalam menerapkan multimodel dalam pembelajaran sesuai dengan fase pertama sampai fase ke lima. Hal ini dapat dibuktikan dari 10 responden 24,04\% memilih sangat setuju bahwa pemanfaatan multi model dalam pembelajaran sangat penting dan bermanfaat, sedangkan $75,96 \%$ mengatakan setuju bahwa pemanfaatan multi model dalam pembelajaran sangat penting dan bermanfaat.
\end{abstract}


Simaremare \& Sianipar - Sosialisasi Pemanfaatan Multimodel dalam Pembelajaran pada Guru SD ...

\section{PENDAHULUAN}

Salah satu hal penting dalam membangun kesejahteraan masyarakat adalah Kualitas pendidikan. Pendidikan dipandang sebagai penyumbang yang sangat besar terhadap kemajuan suatu bangsa [1]. Arah pendidikan bangsa ditujukan untuk menghasilkan sumber daya manusia di Indonesia yang memiliki karakter: setia dan beriman kepada ketuhanan, mulia, sehat, berpengetahuan, terampil, kreatif, mandiri, menjadi warga negara yang demokratis, dan bertanggung jawab [2]. Namun, dalam kenyataannya, kehidupan masyarakat berkembang sangat pesat sedangkan dunia pendidikan ketinggalan dalam menyerap ilmu dan teknologi.

Guru sebagai salah satu elemen dan menjadi ujung tombak dari substansi pendidikan, dituntut untuk memiliki kapabilitas yang prima [3]. Dalam konteks guru sebagai simulator transformasi pengetahuan, guru yang ideal dapat memformulasikan konsep-konsep pembelajaran sedemikian rupa sehingga dapat mencapai sasaran yang hendak dicapai. Sebagai organisator pengajaran di kelas, guru yang ideal harus menyadari bahwa pengajaran itu dapat dikatakan sukses apabila hasilnya tahan lama dan dapat digunakan oleh siswa dalam menjalani kehidupannya, dapat menggunakan apa yang dipelajarinya dengan bebas serta penuh kepercayaan diri di berbagai situasi hidupnya. Dengan demikian, mengajar dapat dikatakan sukses apabila isi pelajaran dapat meaningfull, usefull, dan mengembangkan seluruh aspek pribadi anak.

Dalam kerangka professional, guru harus dapat menguasai dan menerapkan berbagai model pengajaran agar tujuan pembelajaran yang sangat beranekaragam dapat tercapai [4]. Setiap model pengajaran memerlukan sistem pengelolaan dan lingkungan belajar yang berbeda. Setiap pendekatan memberikan peran yang berbeda kepada siswa, pada ruang fisik, dan pada sistem sosial kelas. Tidak ada model pengajaran yang lebih baik daripada model pengajaran yang lain [5]. Oleh Karena itu, guru perlu menguasai dan dapat menerapkan berbagai model pengajaran. Guru yang kreatif akan mengadaptasi model tersebut agar sesuai dengan situasi pembelajaran yang dihadapi sehingga model yang berbeda dapat digunakan secara bersama yang disebut multimodel [6].

Tetapi, dalam pelaksanaannya masih banyak kendala, secara khusus di SD Negeri No. 122372 Pematangsiantar siswa tidak mampu memahami materi pelajaran secara mandiri, siswa merasa jenuh dan bosan selama kegiatan pembelajaran berlangsung, dan dukungan fasilitas yang kurang memadai. Inovasi merupakan pembaharuan yang sejatinya ditujukan untuk memecahkan permasalahan tertentu. inovasi pendidikan adalah pembaharuan dalam pendidikan untuk memecahkan masalah-masalah pendidikan [7]. Berdasarkan kutipan di atas, dapat diartikan pula bahwa inovasi pembelajaran adalah suatu usaha pembaharuan yang dilakukan dalam bidang pendidikan sehingga dapat menghasilkan proses pembelajaran yang lebih baik. Dalam dunia pendidikan, banyak inovasi pembelajaran yang dapat diterapkan dalam pembelajaran, salah satunya yaitu dengan menerapkan inovasi pembelajaran multimodal dalam kegiatan pembelajaran.

Pembelajaran multimodel pada prinsipnya merupakan pendekatan pembelajaran yang secara komprehensif mempertimbangkan kondisi psikologi perkembangan anak, materi pelajaran sebagai objek dan tujuan pembelajaran yang ingin dicapai. Secara teoritis, pembelajaran multimodel berupaya mengimplementasikan berbagai teori dan prinsip belajar yang telah ada serta mengakomodasi potensi dan modalitas siswa dalam belajar (gaya belajar). Menurut DePotter dan Hernacki (2002), secara umum ada dua kategori utama dalam belajar, yaitu bagaimana kita menyerap informasi dengan mudah dan cara kita mengatur dan mengolah informasi tersebut. Gaya belajar tersebut, kemudian dibedakan menjadi modalitas visual, auditorial dan kinestetik.

Hal yang penting menjadi perhatian bagi guru dalam pembelajaran multimodel ini adalah pemeliharaan motivasi siswa agar tetap fokus dalam proses belajar. Dalam hal ini, guru harus kreatif dalam memulai proses belajar, jeli menciptakan kegiatan sela dalam setiap perpindahan fase atau pada setiap term waktu tertentu, serta cerdas dalam mengakhiri setiap fase dan menutup proses pelajaran. Menurut Given (2007), dalam sistem pembelajaran emosional, guru dituntut menciptakan iklim kelas yang kondusif bagi keamanan emosional dan hubungan pribadi untuk siswa agar mereka dapat belajar secara efektif. Guru yang memupuk sistem emosional berfungsi sebagai mentor bagi siswa dengan menunjukkan antusiasme yang tulus terhadap anak didik, dengan membantu siswa menemukan hasrat belajar, dengan membimbing 
mereka mewujudkan target pribadi yang masuk akal, dan mendukung mereka dalam upaya untuk menjadi apapun yang mereka bisa capai. Oleh karena itu, pelajaran harus menarik, menantang, relevan, berkaitan dengan apa sudah diketahui siswa, bisa dicapai, atau berada dalam zona perkembangan proksimal siswa [7].

Dalam proses pembelajaran masih banyak guru yang menggunakan metode konvensional seperti metode ceramah. Metode ini dirasa tidak efektif dan membosankan bagi siswa. Selain kendala yang dialami siswa, para guru juga mengalami kesulitan dalam memberikan materi pembelajaran. Hal ini disebabkan oleh minimnya penguasaan guru SD Negeri No. 122372 Pematangsiantar terhadap ragam model pembelajaran. Selain itu para guru di sekolah tersebut jarang mengikuti pelatihan yang berhubungan dengan model-model pembelajaran. Berdasarkan masalah tersebut salah saatu upaya yang dilakukan oleh tim pengabdi ialah pendampingan pemanfaatan multimodel dalam pembelajaran.

Kegiatan pelatihan ini bertujuan: (1) memberikan pengetahuan kepada guru SD Negeri No. 122372 Pematangsiantar hakikat dan tahap pelaksanaan multimodel dalam pembelajaran; (2) meningkatkan kreativitas guru SD Negeri No. 122372 Pematangsiantar dalam proses pembelajaran di kelas.

\section{METODE PELAKSANAAN}

Kegiatan Pengabdian kepada Masyarakat ini dilaksanakan dalam bentuk sosialisasi dan pendampingan secara tatap muka. Kegiatan sosialisasi ini dilaksanakan pada hari SeninSelasa, 23-24 Oktober 2018 yang dimulai pada pukul 09.00 WIB. Peserta dalam pelatihan ini adalah semua guru yang mengajar di SD Negeri No. 122372 Pematangsiantar yang berjumlah 10 orang. Untuk melihat tingkat keberhasilan guru dalam mengimplementasikan multimodel dalam pembelajaran, tim pengabdi membagikan kuisioner dalam bentuk google form. terkait dengan kegiatan yang telah diikuti Untuk lebih jelasnya, jadwal kegiatan dapat dilihat pada Tabel 1.

\section{Tabel 1. Jadwal Kegiatan Sosialisasi Pemanfaatan Multimodel dalam Pembelajaran} Hari/tanggal Waktu

09.00-09.30 WIB

Senin, 23 Oktober 2018

Sambutan dari kepala sekolah SD Negeri No. 122372 Pematangsiantar, Sambutan yang mewakli tim Pengabdi, dan Pembukaan kegiatan sosialisasi oleh kepala sekolah SD Negeri No. 122372 Pematangsiantar

09.30-10.00 WIB Memaparkan hakikat multimodel Memaparkan langkah-langkah 10.00.11.00 WIB penerapan multi model dalam pembelajaran

Menginstruksikan guru untuk menerapkan multi model dalam

09.00-11.00 WIB

Selasa, 24 Oktober 2018 pembelajaran di kelas bersama peserta yang lain Melakukan evaluasi pelaksanaan 11.00-12.00 WIB model dalam pembelajaran

Kegiatan sosialiasi ini berjalan sesuai dengan prosedur yang telah disusun oleh tim pengabdi sebelum kegiatan dilaksanakan. Prosedur kegiatan tersebut terdiri dari tiga tahap yaitu:

\section{Tahap Persiapan}

Pada tahap persiapan, kegiatan yang akan dilakukan oleh tim pengabdian diantaranya sebagai berikut: (1) Kegiatan ini berawal dari surat undangan dari kepala sekolah SD Negeri 
No. 122372 Pematangsiantar kepada pimpinan Fakultas. Selanjutnya Pimpinan Fakultas menyurati Prodi PGSD untuk mempersiapkan para dosen untuk memberikan sosialisasi penerapan multi model dalam pembelajaran SD Negeri No. 122372 Pematangsiantar. (2) Pimpinan prodi menyurati pimpinan fakultas terkait daftar nama dosen yang ditugaskan dalam memberikan sosialisasi kepada para guru di SD Negeri No. 122372 Pematangsiantar sekaligus memohon kepada pimpinan Fakultas untuk menerbitkan surat tugas kepada dosen yang melaksanakan sosialisasi tersebut. (3) Tim pengabdi melengkapi administrasi termasuk persuratan pada pihak yang berwenang untuk mengetahui pelaksanaan kegiatan pengabdian. (4) Berkoordinasi dengan pihak sekolah SD Negeri No. 122372 Pematangsiantar terkait dengan hal-hal yang dianggap penting dan diperlukan untuk kelancaran kegiatan ini. Sarana dan prasarana yang dibutuhkan serta kesepakatan mengenai persyaratan menjadi peserta dalam kegiatan ini dan batas kuota peserta yang ingin terlibat. Tim pengabdian akan membuat formulir untuk peserta. (5) Menyiapkan materi persentasi pada saat sosialiasi. (6) Menyiapkan jadwal pelaksanaan sosialiasi sekaligus implementasi multi model dalam pembelajaran

\section{Tahap Pelaksanaan}

Sebelum memulai kegiatan pelatihan, terlebih dahulu diawali dengan sambutan dari pihak sekolah SD Negeri No. 122372 Pematangsiantar. Dilanjutkan sambutan yang mewakili tim pengabdi. Selanjutnya kegiatan dilaksanakan tiga sesi dengan rincian sebagai berikut: (1) Sesi pertama, memaparkan hakikat dan langkah-langkah penerapan multi model pembelajaran (Gambar 1 dan 2). (2) Menginstruksikan guru untuk menerapkan multi model dalam pembelajaran di kelas bersama peserta yang lain. (3) Sesi kedua, melakukan evaluasi pelaksanaan kegiatan sosialisasi penerapan multi model dalam pembelajaran

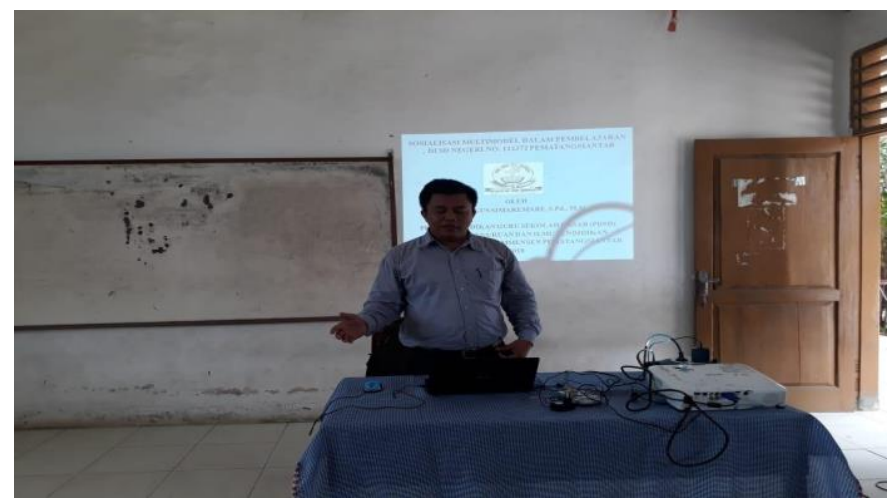

Gambar 1. Pemaparan Hakikat Multimodel dan Penerapannya dalam pembelajaran

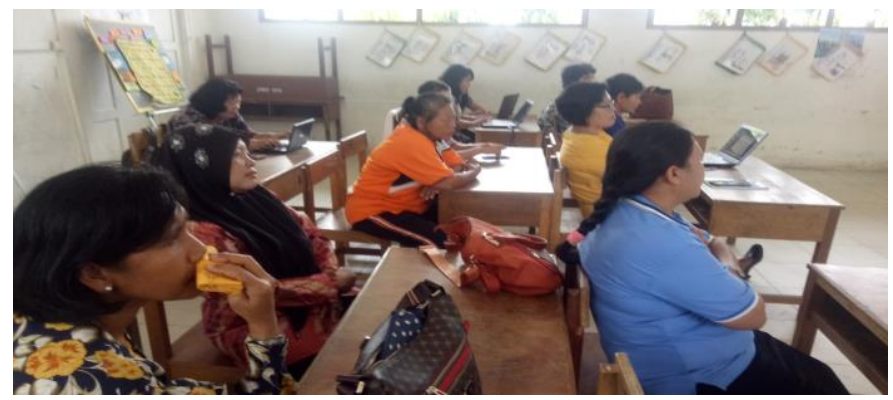

\section{Gambar 2. Para Guru Memperhatikan Pemaparan Penerapan Multi Model dalam Pembelajaran}

\section{Tahap Akhir Kegiatan}

Evaluasi keberhasilan kegiatan sosialiasi dilakukan setelah sesi pemaparan hakikat dan langkah-langkah peneparan multimodel dalam pembelajaran. Indikator keberhasilan kegiatan dilihat dari respon positif dari peserta kegiatan melalui Evaluasi yang diberikan. Kegiatan evaluasi juga dilakukan dengan membagikan kuisioner yang diisi peserta, terkait dengan kegiatan yang telah diikuti. 


\section{HASIL DAN PEMBAHASAN}

Secara umum kegiatan sosialisasa ini dapat berjalan dengan baik dan para guru SD Negeri No. 122372 Pematangsiantar dapat menerapkan multimodel dalam pembelajaran. Dalam penerapannya, guru sudah melaksanakan fase multimodel di kelas bersama peserta yang lain. Fase pertama ialah fase motivasi dan perumusan tujuan. Pada fase ini para peserta sudah melakukan ice breaker, memberikan motivasi, merumuskan tujuan pembelajaran. Fase kedua adalah fase Penyajian data dan orientasi masalah. Pada fase ini guru telah menyajikan materi inti dengan salinng berinteraksi antara guru dengan peserta lain, yang dilanjutkan dengan pemecahan masalah melalui diskusi kelompok. Fase ketiga adalah kajian masalah dan penyelesaiannya, Pada fase para guru telah mempraktekkan pemecahan masalah dari diskusi kelompok yang telah diberikan pada fase kedua. Fase keempat adalah fase Komunikasi/Penyajian hasil, Pada fase ini, guru telah memfasilitasi peserta yang lain mengkomunikasi pemahamannya dan atau menyajikan hasil karyanya untuk dishare kepada peserta yang lain. Fase kelima adalah Refleksi dan Penghargaan/reward, Pada fase ini, para guru telah melakukan refleksi atau evaluasi terhadap aktivitas yang telah dilakukan dan upaya yang dapat dilakukan untuk mengembangkan aktivitas sehingga menjadi lebih baik.

Kemudian untuk mengetahui respon para guru mengenai kegiatan sosialisasi dan pendampingan penerapan multimodel dalam pembelajaran, tim pengabdi juga memberikan kuesioner dalam bentuk google form yang terdiri dari 5 pernyatan dan lima jawaban dalam bentuk skala likert. Pilihan jawaban skala likert tersebut yaitu, (1) sangat setuju, (2) Setuju, (3) ragu-ragu (4) Tidak setuju (5) Sangat tidak setuju. Respon peserta dalam kegiatan sosialisasi tersebut ditunjukkan seperti pada Tabel 2 .

Tabel 2. Respon Pemanfaatan Multimodel Pembelajaran

\begin{tabular}{llccc}
\hline No & \multicolumn{1}{c}{ Pernyataan } & \multicolumn{3}{c}{ Penilaian (\%) } \\
\cline { 2 - 5 } & \multicolumn{1}{c}{$\mathbf{1}$} & $\mathbf{3}$ & $\mathbf{4}$ \\
\hline 1 & $\begin{array}{l}\text { Multi model sangat membantu } \\
\text { guru dalam memberikan materi } \\
\text { dan tugas belajar kepada peserta } \\
\text { didik }\end{array}$ & $20 \%$ & $80 \%$ & \\
\hline 2 & $\begin{array}{l}\text { Pemanfaatan multi model dapat } \\
\text { meningkatkan kompetensi guru } \\
\text { dalam kegiatan pembelajaran }\end{array}$ & $25,3 \%$ & $74,7 \%$ \\
\hline 3 & $\begin{array}{l}\text { Pemanfaatan multi model dapat } \\
\text { membuat interaksi pembelajaran } \\
\text { berjalan dengan baik }\end{array}$ & $33,3 \%$ & $66,7 \%$ \\
\hline 4 & $\begin{array}{l}\text { Pemanfaatan multi model } \\
\text { meningkatkan kreativitas guru } \\
\text { dalam kegiatan belajar mengajar }\end{array}$ & $33,3 \%$ & $66,7 \%$ \\
\hline 5 & $\begin{array}{l}\text { Pemanfaatan multi model } \\
\text { bermanfaat dalam proses } \\
\text { pembelajaran }\end{array}$ & $\mathbf{8 , 3 \%}$ & $\mathbf{9 1 , 7 \%}$ \\
\hline$\quad$ Jumlah & $\mathbf{2 4 , 0 4 \%}$ & $\mathbf{7 5 , 9 6 \%}$ \\
\hline
\end{tabular}

Berdasarkan persentase Tabel 2 dapat disimpulkan bahwa Pemanfaatan multi model sangat penting dan bermanfaat dilaksanakan oleh guru-guru di SD Negeri No. 122372 Pematangsiantar. Hal tersebut dapat dibuktikan dari 10 responden 24,04\% memilih sangat setuju, 75,96\% mengatakan setuju

\section{KESIMPULAN}

Kegiatan sosialisasi multimodel ini telah terlaksana dengan baik sesuai dengan jadwal kegiatan yaitu mulai dari kegiatan awal, inti dan kegiatan akhir. Peserta dalam kegiatan sosialisasi multimode ini para guru SD Negeri No. 122372 Pematangsiantar yang berjumlah 10 orang. Secara umum para guru telah mampu menerapkan multimodel dalam pembelajaran sesuai dengan fase pertama sampai fase ke lima. Pada fase pertama para guru telah 
melakukan ice breaker, memberikan motivasi, merumuskan tujuan pembelajaran. Fase kedua para guru telah menyajikan materi inti dengan saling berinteraksi antara guru dengan peserta lain, yang dilanjutkan dengan pemecahan masalah melalui diskusi kelompok. Fase ketiga adalah para guru telah mempraktekkan pemecahan masalah dari diskusi kelompok yang telah diberikan pada fase kedua. Fase keempat para guru telah memfasilitasi peserta yang lain mengkomunikasi pemahamannya dan atau menyajikan hasil karyanya untuk dishare kepada peserta yang lain. Fase kelima para guru telah melakukan refleksi atau evaluasi terhadap aktivitas yang telah dilakukan dan upaya yang dapat dilakukan untuk mengembangkan aktivitas sehingga menjadi lebih baik. Keberhasilan para guru juga dapat dibuktikan dari 10 responden $24,04 \%$ memilih sangat setuju bahwa penerapan multi model dalam pembelajaran sangat penting dan bermanfaat, sedangkan $75,96 \%$ mengatakan setuju bahwa penerapan multi model dalam pembelajaran penting dan bermanfaat.

\section{UCAPAN TERIMA KASIH}

Ucapan terima kasih kami sampaikan kepada Pimpinan Universitas HKBP Nommensen Pematangsiantar, Pimpinan Fakultas Keguruan Ilmu Pendidikan Universitas HKBP Nommensen Pematangsiantar, Pimpinan Lembaga Penelitian dan Pengabdian kepada Masyarakat, dan Pimpinan Program Studi Pendidikan Guru Sekolah Dasar. Ucapan terima kasih juga kami sampaikan kepada tim dan kepada kepala sekolah serta para guru SD Negeri No. 122372 Pematangsiantar.

\section{DAFTAR PUSTAKA}

[1] U. Amri, "Pengaruh Biaya Pendidikan terhadap Keputusan memilih Lembaga Pendidikan," EDUKATIF J. ILMU Pendidik., vol. 3, no. 5, pp. 2355-2361, 2021, doi: https://doi.org/10.31004/edukatif.v3i5.786 Copyright.

[2] H. Habe and A. Ahiruddin, "Sistem Pendidikan Nasional," EKOMBIS SAINS J. Ekon. Keuang. dan Bisnis, vol. 2, no. 1, pp. 39-45, 2017, doi: 10.24967/ekombis.v2i1.48.

[3] S. Nuralam, "Analysis of Teacher Service Quality on Minimal Completeness Criteria Achievement in Mathematics Learning of Students at SMAN 6 Jenepont," J. Inov. Pendidik. Mat., vol. 6, no. 2, pp. 203-213, 2018.

[4] Safnina, "Penerapan Model Pembelajaran Kooperatif Tipe Snowball Throwing Untuk Meningkatkan Hasil Belajar Sejarah Siswa Kelas XI IIS 2 Semester Genap SMA N 1 Pinggir Tahun Pelajaran 2018 / 2019," J. Pendidik. Tambusai, vol. 5, pp. 3848-3861, 2021.

[5] Suparman, "Upaya Meningkatkan Prestasi Belajar Teknik Pembentukan dan Perakitan Fabrikasi Logam Melalui Metode Pembelajaran Kooperatif Model STAD (Student Teams Achievement Division) Pada Siswa Kelas XII TFL 2 SMK Negeri 58 Jakarta," PROFESI (Jurnal Ilmu Pendidik. dan Keguruan), vol. 9, no. 1, pp. 14-25, 2020

[6] R. Santaria, "Dampak Pandemi Covid-19 terhadap Proses Pengajaran bagi Guru dan Siswa Pendahuluan," J. Stud. Guru dan Pembelajaran, vol. 3, no. 2, pp. 289-295, 2020.

[7] T. Kadi and R. Awwaliyah, "Inovasi Pendidikan: Upaya Penyelesaian Problematika Pendidikan Di Indonesia," J. Islam Nusant., vol. 1, no. 2, pp. 144-155, 2017, doi: 10.33852/jurnalin.v1i2.32 